\title{
Anadolu'da Asur Ticaret Kolonileri Çağ1
}

\section{Öz}

Anadolu tarihi açısından Asur Ticaret Kolonileri Çağı ayrı bir öneme sahiptir. Bu çağda Anadolu’ya yazı gelmiş ve uygarlı̆̆ın gelişiminde çok önemli bir aşama olan tarihsel süreç böylece başlamıştır. Karum ve Wabartum adı verilen iki önemli ticaret merkezinden oluşmaktadır. Kaneş, Hattuş ve Alişar tablet bulunan en önemli üç merkezdir. Kaneş, Anadolu'da bulunan tüm koloniler için aynı zamanda bir merkez konumundadır. Ticaretin temelini Asur'dan Anadolu’ya kalay ve dokuma ürünleri ile Anadolu'dan Asur'a yapılan altın, gümüş ve bakır ihracatı oluşturur. M.Ö. 1945-1730 yılları arasını kapsayan bu dönem dört tabaka meydana getirmiştir. Bu tabakalardan arkeolojik belgeler yanında yazılı tabletler de çıkarılmıştır. Tabletler II ve $1 \mathrm{~b}$ tabakalarında bulunmuştur. Tüccarlar ticaret mallarını genellikle eşekler yoluyla taşırlardı. Bu eşekler yaklaşık 1000 kilometrelik yolu takriben 10 haftada alıyorlardı. Bağımsız olarak yola çıkan kervanlar yolda bir araya gelerek konvoylar oluşturmaktaydılar. Asur ile Anadolu arasında gelip giden bu kervanlar genellikle 3 anayol üzerinde hareket etmekteydiler. Asur ile Anadolu arasında yapılan ticaret çeşitli kalem vergilerle yerli beylere ve Asur'a önemli bir gelir sağlıyordu. Ticareti yasaklanmış olan veya kısıtlanan malları alıp satmak yoluyla kaçakçılık yapıldığını da görmekteyiz. Asur'dan Anadolu'ya uzanan bu ticaret ağı sayesinde, Anadolu'da yazıya geçilmiş ve böylece Anadolu'da tarih başlamıştır. Bu açıdan bakıldığında Asur Ticaret Kolonileri Çă̆ı'nın Anadolu için önemi çok daha iyi anlaşılmaktadır.

Anahtar Kelimeler: Kaneş, Hattuş, Alişar, Asur Ticaret Kolonileri, Karum.

\section{Assyrian Trade Colonies Era in Anatolıa}

\section{Abstract}

As a part of Anatolian history, Assyrian trade colonies era has a great importance. In this era, writing came to Anatolia and historical span which is very important step in the development of the history began. It consists of two important trade centers: Karum and Wabartum. Kaneş Hattuş and Alişar which are three important centers which tabloids were found. Kaneş was the center for all Anatolian colonies. The basis of trade is with tin and weaving products from Assyria to Anatolia exported from Asur to Anatolia and gold; silver and copper exported from Anatolia to Assyrian. This era between 1945 B.C and 1730 B.C consists of four layers. Not only archaeological documents but also writing tabloids were excavated from these layers. Tabloids were found in II and $1 \mathrm{~b}$ layers. The traders usually carried their goods on donkeys. These donkeys took approximately 1000 kilometers of road in about 10 weeks. The caravans would independently set out on the road and come together on the way to form convoys. These caravans which went back and forth between Assyria and Anatolia generally moved on 3 main roads. The trade between Assyria and Anatolia provided a significant income for the local beys and Assyria in general through the tax put on various items. It is known that smuggling was also done as prohibited or limited goods were bought and sold as well. Due to this trade network which extends from Assyria to Anatolia, writing was adopted in Anatolia and thus history began in Anatolia. From this point of view, the importance of the Assyrian Trade Colonies Age for Anatolia is much better understood.

Keywords: Kaneş, Hattuş, Alişar, Assyrian Merchants, Karum. 


\section{Giriş}

Asur Ticaret Kolonileri Çağ1 denildiğinde, bunun Anadolu'da bir Asur egemenlik çağ1 olarak algılanması yanlış olur. Bu dönem Asur ile Anadolu arasında ticari ilişkilerin yoğunlaştığı ve bu yoğunluğun karşılıklı menfaatler ile kazanıma dönüştüğü uluslararası bir ilişkidir. M.Ö. 1945 ile 1730 y1llar1 aras1 Anadolu tarihinde Asur Ticaret Koloni Çağ1 olarak nitelendirilir (Özgüç 2002: 402). Buna göre merkezi Mezopotamya'daki Asur bölgesi olan Asurlu tüccarlar, Anadolu'da Kayseri yakınlarındaki Kültepe/ Kaneş'de olduğu gibi bugün adları bilinen ve bilinmeyen bazı yerleşmelerin yakınlarında pazar yerleri kurarak getirdikleri malları buralarda satmak yoluna gitmişler, buradan aldıkları malları da Asur’a götürerek orada pazarlamışlardır.

\section{Karumlar ve Wabartumlar}

Bu ticaret sisteminin iki önemli ayă̆ı vardır. Birincisi "Karum" ve diğeri de "Wabartum" adı verilen merkezlerdir. Karum Asur dilinde liman ve rihtım manasına gelmekte olup, buralar büyük pazar yerleri ve yerleşmeleridir. Bu ticaret merkezleri, bir nevi bu günkü serbest ticaret yerleri gibi de düşünülebilir. Bu sistemin diğer ayağı olan Wabartumlara gelince; bunlar ana merkezler arasında gidip gelen tüccarların konakladıkları, mallarını depoladıkları bir nevi kervansaraylar gibi de düşünülebilir. Wabartum kelimesi "misafir" anlamına gelmektedir (Dinçol 1982: 21). Bu dönemde sadece Asurlu tüccarlar değil, Suriyeli ve Mezopotamyalı tüccarlar da Anadolu ile ticaret yapmışlardır. Siyasi ve adli bakımdan Asur devletine bağlı olan Asurlu tüccarlar, Asur'da kurdukları birçok şirket üzerinden ticaret yapmaktaydılar ve bunların büyük bir kısmı aile şirketlerinden ibaret idi (Şahin 2004:1). Anadolu'daki Karumlar arasında en tanınmış olanı Kültepe'de bulunan Kaneş'tir. Burada yapılan kazılarda çok sayıda tablet ele geçmiştir. Boğazköy'de bulunan Karum Hattuş ile Alişar'da bulunan ve eski adını bilemediğimiz diğer bir Karum’da önemli koloni Karumları arasında zikredilmektedir (Dinçol 1982: 21-22).

\section{Kolonilerin Coğrafi Dağılımı}

Kolonilerin yayıldığı alan tam olarak tespit edilememiştir. Tespit edilenler dişında kalanların Malatya-Kayseri-Yozgat üçgeni içinde bulundukları sanılmaktadır (Kınal 1987: 62). Kuzey Suriye ve Anadolu'da yaklaşık 30 Karum ile yine 30 civarında Wabartum oluşturulan bu ticaret ağının içinde idi (Koçak 2009: 211; Bayram 1996: 35).

\section{Kolonilerde Alım-Satım Yapılan Ticaret Malları}

Anadolu ile Asur arasinda yapilan ticarette genel olarak Asur'dan Anadolu'ya kalay ve dokuma ürünleri getirilirdi. Anadolu'dan Asur'a ise genel olarak gümüş ve altın ile bakır satımı söz konusuydu. Bu arada maden filizi, kereste, kürk, deri, meteorik demir ve arpa satılmaktaydı. Asurluların Anadolu’ya getirdikleri kalayı Anadolu dışından aldıkları anlaşılmaktadır. Çünkü Anadolu'da kalay yoktur. (Larsen 1996: 158). Anadolu kalay bakımından diğer yörelere nazaran biraz daha yoksul idi (Macguen 2001: 19). Asur'dan gelen tekstil mallar1 ise kocalar1 Anadolu'da seferde olan kadınların dokudukları ve başka bölgelerden getirilen hammaddelerin değerlendirilmesi yoluyla yapıldığı bilinmektedir. Asur'daki kolonilerin Mezopotamya ve İndus bölgesine kadar uzandıkları bilinmekle beraber oradan getirilen malların Anadolu'da satıldığına dair bir kayıt bulunamamıştır.

\section{Koloni Ticaretinde Mal Taşıma Şekli ve Önemli Kervan Yolları}

Tüccarlar ticaret mallarını genellikle eşekler yoluyla taşırlardı. Eşekler Asur'da çayırdayken satın alınırdı. Tüccarlar genellikle kara eşekleri tercih etmekteydiler. Yaklaşık 1000 kilometrelik bir yolları vardı. Bu yolu eşeklerle takriben 10 haftada alıyorlardı (Veenhof 1972: 45). Bağımsız olarak yola çıkan kervanlar yolda bir araya gelerek konvoy oluşturmuşlardır. Bu eşekler için eşek sürücüleri ve rehberler (SARRIDUM) kiralanmaktaydı (Garelli 1963: 301). Bunlara da taşınan eşyaların idaresinden sorumlu olan bir aracı (KASSARUM) eşlik etmekteydi. Tabletlerden bu 
kervanların vurulma tehdidiyle karşılaştıkları anlaşılsa da bunun ticareti sona erdirecek bir yoğunlukta olmadığı görülmektedir. Asur ile Anadolu arasında gelip giden bu kervanlar genellikle 3 anayol üzerinde hareket etmekteydiler. Bu yolların ilki, kuzeyde bulunan Musul'dan hareket ederek Dicle Nehri istikametinde kuzeye doğru gidiyor ve batıya doğru dönerek Midyat, Diyarbakır, Malatya, Darende, Gürün ve Pınarbaşı üzerinden Kaneş'e gelen yoldur. Diğeri ise Dicle Vadisi'nde bir yerde batıya doğru dönerek Urfa, Birecik, Gaziantep, Adana ve Gülek geçidini geçerek Kappadokia'ya ulaşan yol idi. Üçüncü güzergâhta ise Gaziantep’ten kuzeye doğru dönerek Pazarcık, Maraş, Elbistan, Sarız, Kuruçay, Pazarviran üzerinden Kaneş’e ulaşmaktaydı (Yakar 2007: 38). Yerel kralların tüccarların mallarına koruma garantisi de verdikleri bilinmektedir. $\mathrm{Bu}$ bölgede ticaretin artması için gelir artırıcı bir taahhüt olarak da düşünülebilir. Kervanlar yoldayken bazı yerel prenslerin sağladığı korumalar tarafindan bu güvenlik sağlanmakta ve masraflarda tüccarın masraflarına dâhil edilmekteydi. Bu korumalar için tüccarın bazen 1 MINA gümüş (Yaklaş1k 500 gr) veya 4 şekel gümüss paralar ödediği belirtilmektedir (Garelli 1963: 300303; Yakar 2007: 38).

\section{Tüccarların Ödedikleri Vergiler}

Bu ticaret mallarından \%100'e yakın bir kar sağlandığ1 bilinmektedir. Özellikle tunç alaşımında kullanılan kalayın çok karlı bir ticaret malı olduğu belgelerden anlaşılmakla beraber yine alıcının borçlanarak alışveriş yapması durumunda \%30 civarında da faiz ödemesi söz konusu olmaktaydı. Karumlarının bulunduğu mahallin kralları bu ticaretten vergi almakta olup bu oran dokumadan 1/20, kalaydan 2/65 oranına tekabül ederdi. Kervanın geçtiği yolun üzerindeki krallara ise $\% 10$ oranında yol vergisi ödemekteydiler. Bazı malların alım satımı ise tamamen yerel kralların kontrolü altında olup bu malları kaçak olarak sokmaya çalışan ve yakalanan bazı kaçakçılarında varlığı belgelerden anlaşılmaktadır (Dinçol 1982: 22).

Asur ile Anadolu arasında yapılan ticaret çeşitli kalem vergilerle yerli beylere ve Asur'a gelir sağlıyordu. Bu vergiler arasında tekstil ürünlerinden kalaydan ve gümüşten alınan Nishatum, Anadolu'da Karum dairesine ve Asur'da bet-alim'e yani şehir devletine ödenen \%2 saddü'atum, yol vergisi olarak bilinen Tatum, Qaggadatum/kafa vergisi, E/İsratum/öşür vergisi, Wasitum/ihraç vergisi veya kervanın ilk hareketinde alınan vergi, Eriptum/giriş vergisi, Karum dairesine yapılan yüzde 5 lik Metum Hamsat vergisi önemli yer tutmaktaydı (Koçak 2009: 222; Bayram 1993: 6-12). Alınan tüm bu vergiler beraberinde kaçakçllı için kap1 açmaktaydı. Tüccarlardan bazıları yerel saraydan gümrük izni almadan malı şehre sokmak veya güzergâhtaki yerleşim yerlerindeki ödemelerden kurtulmak için kestirme, kullanışsız ve güçlükle aşılan yolları takip ederek yapılıyordu. Ticareti yasaklanmış olan veya kısıtlanan malları alıp satmakta bir başka kaçakçılık türü olarak karşımıza çıkmaktadır. Tüccarlardan kaçakçılık olaylarına karşı bir tedbir olarak kutsal bir alan olan "hamrum" odasında yemin alınmaktaydı (Gökçek 2009: 147).

\section{Asur Ticaret Kolonilerinde Hukuki Uygulamalar}

Bu arada Anadolu'da görev yapan Asurlu tüccarların Anadolu'da yerel beyler ile ticari ilişkilerini düzenlemede onlara yardımc1 olan bazı Asurlu görevliler bulunmaktaydı. Asurlular Asur'daki yönetimlerinin bir benzerini Anadolu'da bulunan koloni şehirlerde tesis etmek istemişlerdi. Asur'da kralın yanında bulunan büyük ve küçük meclisin bir örneğini burada da oluşturmuşlardı. Bunlar arasında sipru sa alim.ki /Asur şehrinin elçisi, sipru sa Karim Kaniş / Kaniş Karumunun Elçisi, Sagil - datim /Sadduatum vergisini toplayan görevli, Aliku Sa Harran Alim.ki /Asur Şehir Meclisinin temsilcisi, Usbutim / Wasbuni = muhtemelen Karumlardaki hakimler, Biritum / Karumlarda Usbutim olarak geçen büyük adamların yerine wabartumlarda görev yapan seçilmiş şahıs, Nibum= ?, rabi sikk.katim /maden ticaretinden sorumlu kişi, rabisu sa alim. Ki /asur şehrinin avukatı sayılabilir. Bunlardan başka tabletlerden tespit edilmiş kırk civarında "Rabi" ile başlayan unvan tesbit edilmiştir. Kelime analizlerinden anlaşıldığ 1 kadarıyla rabi maşşartim=depo amiri, rabi kakki=silahtar başı, rabi şabim=işçi başı, rabi hursatim=ormancılar başı, rabi alpatim 
=sığır sürücülerinin başı, rabi sükallim=baş vezir, rabi şerim=tarlalara bakan memur başı, rabi sage $=$ sakler başı, rabi re'im $=$ çobanlar başı, rabi alahhinim $=$ vekil harç, rabi kalbatim $=$ köpek bakıcılarının başı, rabi aslakim=çamaşırcılar başı, rabi abullatim $=$ kap 1 memuru, rabi sise=atlar başı, seyis, rabi mahirim=pazarbaşı ağası, rabi askapim $=$ dericiler başı, rabi paşuri $=$ sofracı başırabi hatim $=$ asacı, rabi nagiri=tela başı, rabi nappahe=demirci başı (Gül 2002: 45).

Ticaret kolonilerindeki kayıtlardan anlaşıldığına göre Karumlarda bulunan kutsal Hamrum odasında mahkeme yapıldığını belgelerden öğrenmekteyiz (Şahin 2002: 69-88). Anadolu'da Karumlarda bulunan tüccarlar arasındaki davalar burada çözülemez ise bir belge düzenlenerek Kaneș Karum'una gönderiliyor ve orada sonuçlandirlliyordu bu davalar Kaneș Karum'unda çözülemezse halledilemeyen davalar Asur'a gönderiliyordu. Bu kutsal Hamrum odasında Şehir Meclisi davayı çözerek bir avukat aracıllğ̆1yla Kaneş Karum’una yolluyordu (Şahin 2006: 122-123). İdari teşkilat içerisinde wakkum/vekil kontrolör olarak adlandırılan yüksek dereceli memurlarda yer almaktadır (Gül 1993: 45). Rabi similtim ve rabi sikkatim adlı iki görev daha bulunmakta olup rabi similtim görevinin veliahdlık ve rabi sikkatim görevinin ise askeri bir rütbe olduğu kesin olmamakla birlikte tahmin edilmektedir. Bir y1llık bir süre için görevlendirilen Limum ve Hamutsum denilen 5 üyeden oluşan özel bir komite de vardı. Bahsi geçen bu görevlerde bugün tam olarak ne yaptıkları bilinememekle beraber tabletlerde geçen görevler olarak tarih sayfalarında yerini almıştır (Gül 1993: 45).

Asurluların büyük șehirlerde birer Karum ve küçük şehirlerde ise birer Wabartum teșkilatları vardı. Tabletlerden öğrendiğimize göre örneğin Kaneș Karum'unda "șehrin babaları" denilen bir ihtiyar meclisi vardı. Asurlular hakkındaki kararlar burada verilirdi. Burada bir anlaşmazlık olursa İhtiyarlar Meclisi kâtibi genel meclisi toplantıya çă̆ırırdı. Burada sayı hesabıyla karar verilirdi. Bu meclislere büyük ve küçük Karum adı verilirdi. Kolonistler arasındaki davalara Karum veya Wabartum idare heyetleri bakmakta olup bazen de "beștebirler" denilen idare heyetleri bakardı. Son hüküm yani bugün ki manada temyiz hakkı Asur şehrinde idi (Kınal 1987: 62; Şahin 2006,121-151)

Asur ile Anadolu arasındaki bu alışveriş kültür iletişiminde çok fazla bir etki göstermemiştir. Bu kolonilerin nasıl ve ne şekilde sona erdiği bilinmemekle beraber bunun büyük bir yıkım neticesinde olduğu anlaşılmaktadır. Karum II ve Ib tabakalarındaki yangın buna kanıt olarak gösterilmektedir. Ib’de yeniden bir canlanma izleri görülse de eski canlılığına kavuşmadan Asur ile bağların tamamen yok olduğu görülmektedir. Bu dönemde Anadolu'da güçlü bir merkezi otoritenin varlığ1 söz konusu değildir. Bu dönemlerde yerel kent kralları mevcut olup bunlar arasında kıyasıya bir rekabet, ihtilaflar ve ittifaklar söz konusudur (Dinçol 1982).

\section{Anadolu'da Önemli Karumlar}

Asur Ticaret Kolonileri veya Kültepe çağı olarak da adlandırılan bu devirde özellikle Orta Anadolu'da etrafi surlarla çevrilmiş, krallıkla idare olunan birçok şehir ortaya çıkmıştı. Bu şehir devletleri ile Mezopotamya ve Kuzey Suriye şehirleri arasında canlı bir dış ticaret bağı vardı. $\mathrm{Bu}$ ticareti de Asurlu kolonistler elde tutmaktaydı (Kınal 1987: 71). Belirtildiği gibi Asur ticaret kolonileri Karum ve Wabartumlardan oluşmakta olup metinlerde adı geçen bazı Karumlar, Hahhum, Hattuş, Kaneş, Hurama, Nihriia, Puruşhattum, Turhamit, Wahşuşana, Eluhut, Ursu, Zalpa, Tamnia, Luhuzattia, Washaniadır. Wabartumlar ise Hanak'nak, Ma'ma, Patna, Tuhpia, Ulama, Salatuwar, Karahna, Washania, Zalpa ve Ankuwa'dan oluşmaktadır (Gül 1993: 44; Götze 1957: 74-75).

Anadolu'daki Karumlar arasında en ünlüsü ve diğer Karumlarında arasında bulunduğu idare merkezi Kaneş Karumu'dur. Diğer Karumlar Kaneş'e, Kaneş’te Asur'a bağliydı. Bu Karumların birçoğunun yeri belli değildir. Tüm Karumlar hakkında bilgi kaynağımız şu an Kaneş Karumu'dur.(Şahin 2004: 1-118) Bu Karumların yönetim merkezi olan Asur'da bunlar hakkında bir bilgi. Karumların yönetim merkezi Orta Anadolu platosunda Kaneş Karumu'dur. Kültepe’den 
başka bu tabletlerden Boğazköy'de 64, Alişar'da 70 ve Kalehöyük'te 4 adet tablet bulunmuştur. Bu tabletlerden Kuzey Mezopotamya'da Asur, Nuzi, Yorgantepe, Suriye'de Mari ve Tell Leilan'da bulunmuştur (Özgüç 2002: 12). Karumlar da inşa edilen evler yerli ustaların eseriydi. Bu evler çok odalı, taş temelli ve kerpiçten yapılmaktaydı. (Akurgal 1999:43) Anadolu'da ticareti yapılan malların en önemlisi meteorik demir ve (amutum ve asium) kıymetli taş (huşarum) idi. Asurlular kendi aralarında altın karşıllı̆ında ticaret yapabilirlerdi ancak bir Asurlunun yabancılara altın satması yasaklanmıştı. Asurlular amutumu altın ve gümüş karşıllğında satmaktaydılar. Amutum için saray depolarında bol miktarda bakır bulundurulurdu (Özgüç 2002: 15). Asur Ticaret Kolonileri olarak adlandırılan bu çağ Anadolu için aynı zamanda tarihin başlangıcına oluşturmaktadır. Bugün yapılan kazılarda dört kültür tabakasının varlığı görülmektedir. Yazılı belgeler 1. tabakanın b evresinde bulunmuştur. Bu tabaka Asur kralı Şamsi-Adad zamanına tarihlenmektedir. Bu çağın kronolojisi Kaneş Karumu'na göre düzenlenmektedir (Bahar 2010: 252).

\section{Sonuç}

Asur Ticaret Kolonileri Çăğ, Anadolu'da tarihin başlamasına neden olan en önemli bir tarihsel süreçtir. Karum ve Wabartum adı verilen iki tür ticaret merkezi bulunmaktaydı. Yaklaşık olarak M.Ö. 1945-1730 yılları arasını kapsar. Onlarca Karum içerisinde Kaneș, Alişar ve Hattuş en önemlilerini oluşturur ki bu Karumlardan aynı zamanda yazılı tablette çıkarılmıştır. Kaneş bütün Anadolu Karumları arasında en önemlisi idi. Asur Ticaret Kolonileri Çağ1 kronolojisi Kültepe/Kaneş Karumu üzerinden ayarlanmaktadır. Ticaretin temelini Asur'dan Anadolu'ya kalay ve dokuma ürünleri ile Anadolu'dan Asur'a altın, gümüss ve bakır oluşturmaktaydı. Asur ile Anadolu arasında hareket eden bu kervanlar 3 ana güzergâhı takip etmekteydiler. Bunlardan ilki Musul'dan hareket ederek Dicle istikametinde kuzeye doğru gidiyor ve batıya doğru dönerek Midyat, Diyarbakır, Malatya, Darende, Gürün ve Pınarbaşı üzerinden Kaneş’e gelen yoldur. Diğeri ise Dicle vadisinde bir yerde batıya doğru dönerek Urfa, Birecik, Gaziantep, Adana ve Gülek geçidini geçerek Kappadokia’ya ulaşan yol idi. Üçüncü güzergâh ise Gaziantep’ten kuzeye doğru dönerek Pazarcık, Maraş, Elbistan, Sarız, Kuruçay, Pazarviran üzerinden Kaneş’e ulaşmaktaydı. Bugün Kayseri-Çorum-Yozgat üçgeni içerisinde kalan Anadolu'nun bu en eski ticaret merkezleri bu özelliğini ilginç bir tevafukla yine devam ettirmektedir.

\section{Kaynakça} Kitaplar1.

AKURGAL, Ekrem (1999). Anadolu Kültür Taribi, Ankara, Tübitak Popüler Bilim

BAHAR, Hasan (2010). Eskiçağ Uygarlıklar, Konya: Kömen Yayınevi.

BAYRAM, Sabahattin (1996). "Koloni Çağında Kayserinin Ticari Hayatı", E.Ü. 1. Kayseri ve Yöresi Tarih Sempozyumu Bildirileri 1996. Kayseri, 405-416.

BAYRAM, Sabahattin (1993).“Kültepe Tabletlerinde Geçen Vergiler ve Özellikleri”, Ankara Üniversitesi, Dil ve Tarih Coğrafya Fakültesi Dergisi, 36(1-2): 1-13.

DİNÇOL, Ali (1982). "Hititler”, Görsel Anadolu Uygarllklarn Ansiklopedisi, Görsel Yayınlar, C1, İstanbul, ss. 18-137.

EYÜPOĞLU, İsmet Zeki (1981). Anadolu Uygarlğ̆g, İstanbul: Derin Yayınları.

GARELLI, Paul (1963). Les Assyriens en Cappadoke, Bibliothegue archeologigueet historigue de l'institut francais d'archeologie d'istanbul 19, Paris.

GÖKÇEK, Gürkan (2009). "Çivi Yazılı Tabletlere Göre Eski Anadolu'da Vergi Uygulamaları ve Kaçakçılık (M.Ö.1975-1750)”, Akademik Bakış, 2(4): 147-155.

GÖTZE, Albrecht. (1957). Kleinasien. Kültürgesichte des alten Orients III,1. München. 
GÜL, Şerife (1993). “Asur Ticaret Kolonileri Çağında Anadolu'nun Siyasi Yapısı. The Political Construction of Anatolia During the Assyrian Colonies Period", Systematik qur Hetbitischen Bibliographie, s. 42-49.

KINAL, Füruzan (1987). Eski Anadolu Taribi, İstanbul: Türk Tarih Kurumu Yayınları.

KOÇAK, Kürşat (2009). “Asur Ticaret kolonileri Çağında Ticareti Yapılan Mallar ve Vergiler”, Erciyes Üniversitesi Sosyal Bilimler Enstitüsü Dergisi, 27(2): 209-226.

LARSEN, Mogens Trolle (1996), Eski Asur da Kervan Dökümleri, İstanbul: Nederlands Historics-Archaeologisch Institut.

Arkadaş Yayınevi.

MACGUEN, J.G. (2001). Hititler ve Hitit Çă̆ında Anadolu, çev. Esra Davutoğlu, Ankara:

ŞAHIN, Hasan Ali (2002). “Koloni Çağı'nda (M.Ö. 2000-1750) Anadolu'da Bulunan Asurlu Görevliler", Erciyes Üniversitesi Sosyal Bilimler Enstitüsü Dergisi, 12: 69-88.

ŞAHIN, Hasan Ali (2004). Anadolu'da Asur Ticaret Kolonileri Devri (M.Ö. 1975- 1725), Kayseri: E.Ü. Kayseri ve Yöresi Tarih Araştırmaları Merkezi Yayınları.

ŞAHIN, Hasan Ali (2006) “Anadolu'daki Eski Asur Koloni Mahkemeleri”, Erciyes Üniversitesi Sosyal Bilimler Enstitïsü Dergisi, 21: 121-151.

VEENHOF, Klaas Roelof (1972). Aspeckts of old Assyrian Trade and its Terminology, Leiden London. Kitabevi.

YAKAR, Jak (2007). Anadolu'nun Etnoarkeolojisi, çev. Selen Hırçın Riegel, İstanbul: Homer 